\title{
First report of powdery mildew of coastal wattle (Acacia sophorae) caused by Erysiphe quercicola
}

\author{
Anthony Young ${ }^{1}\left[\right.$ [ $\cdot$ Levente Kiss $^{2}$ (i)
}

Received: 8 December 2020 / Accepted: 22 February 2021 / Published online: 23 March 2021

(c) Australasian Plant Pathology Society Inc. 2021

\begin{abstract}
A powdery mildew was found associated with the coastal wattle, Acacia sophorae, at Tullymorgan, in northern New South Wales, Australia. Morphological characterisation identified it as belonging to the genus Erysiphe, while internal transcribed spacer (ITS) sequencing and phylogenetic analysis confirmed it as Erysiphe quercicola, a pathogen with a worldwide distribution and a broad host range. This is the first record of E. quericola infecting A. sophorae, and the first powdery mildew infection recorded for this native Australian plant.
\end{abstract}

Keywords Powdery mildew · Australian flora

Coastal wattle (Acacia sophorae) is a shrub native to coastal and subcoastal south-eastern Australia. It is part of the vegetation of coastal heaths and forests, and also dunes as it tolerates sea sprays and sand blasts. In July 2020, heavy powdery mildew infections were observed on the leaves of A. sophorae in an open woodland forest at Tullymorgan, New South Wales, Australia. Whitish powdery mildew mycelium covered large parts of the abaxial leaf surfaces (Fig. 1a). Ten powdery mildew-infected leaves were collected from the spot, and pressed and dried for a week to produce specimens that were deposited at the Queensland Plant Pathology Herbarium under accession number BRIP 71600. A part of the herbarium material was taken to the laboratory for further investigations.

Morphological characteristics of hyphae, conidiophores and conidia were observed following rehydration of small samples of the powdery mildew mycelium using a method modified after Shin and La (1993). First, mycelial samples were removed from the dried leaves with $3-4 \mathrm{~cm}$ long pieces of cellotape. Each cellotape piece was immediately placed with mycelia downwards in a droplet of $100 \% \mathrm{v} / \mathrm{v}$ lactic acid pipetted onto a microscope slide. The slides were

Anthony Young

anthony.young@uq.edu.au

1 School of Agriculture and Food Sciences, The University of Queensland, Brisbane, Australia

2 Centre for Crop Health, University of Southern Queensland, Toowoomba, Australia gently heated over an alcohol burner flame until boiling, then the cellotape pieces were lifted with a forceps, and the mycelial samples were scraped off with a scalpel into the lactic acid drops on the slides. The cellotape pieces were then removed, and a coverslip placed over the fungal samples. Slides were examined under a Nikon Eclipse Ni-U microscope (Nikon Co., Tokyo, Japan) with bright field and differential interference contrast (DIC) optics. Conidiophores produced conidia singly, and consisted of a foot-cell, straight or occasionally slightly curved-sinuous at the base, $22-41 \times 7-12 \mu \mathrm{m}$, basal septum at the branching point, followed by one or two cells up to the same length as the foot-cell (Fig. 1b, c). Conidia were cylindrical or ellipsoid-cylindrical, and occasionally doliiform, 24-41 $\times 12-21 \mu \mathrm{m}$. Germinating conidia were also observed in the rehydrated materials. These produced germ tubes terminally or subterminally, ended in mostly multi-lobed appressoria, and were up to 3-4 times longer than conidia. Hyphal appressoria were also lobed or multi-lobed. All these morphological characteristics were diagnostic of the genus Erysiphe, but did not reveal the identity of the powdery mildew fungus at the species level.

To support the identification of the pathogen with molecular tools, total genomic DNA was extracted from powdery mildew mycelial samples removed from the host plant surfaces with $1-1.5 \mathrm{~cm}^{2}$ pieces of cellotape. Cellotape pieces with mycelia were placed in $1.5 \mathrm{ml}$ eppendorf tubes and DNA was extracted using the buffers of an Extract-NAmp Plant PCR kit (Sigma-Aldrich, St. Louis, MO, USA) 
Fig. 1 a Acacia sophorae leaves infected with powdery mildew in New South Wales, Australia. b An immature conidiophore of Erysiphe quercicola removed from an A. sophorae leaf following rehydration in hot lactic acid. c A mature conidiophore of Erysiphe quercicola removed from an A. sophorae leaf following rehydration in hot lactic acid. Bars $=10 \mu \mathrm{m}$. Images were edited using Adobe Photoshop
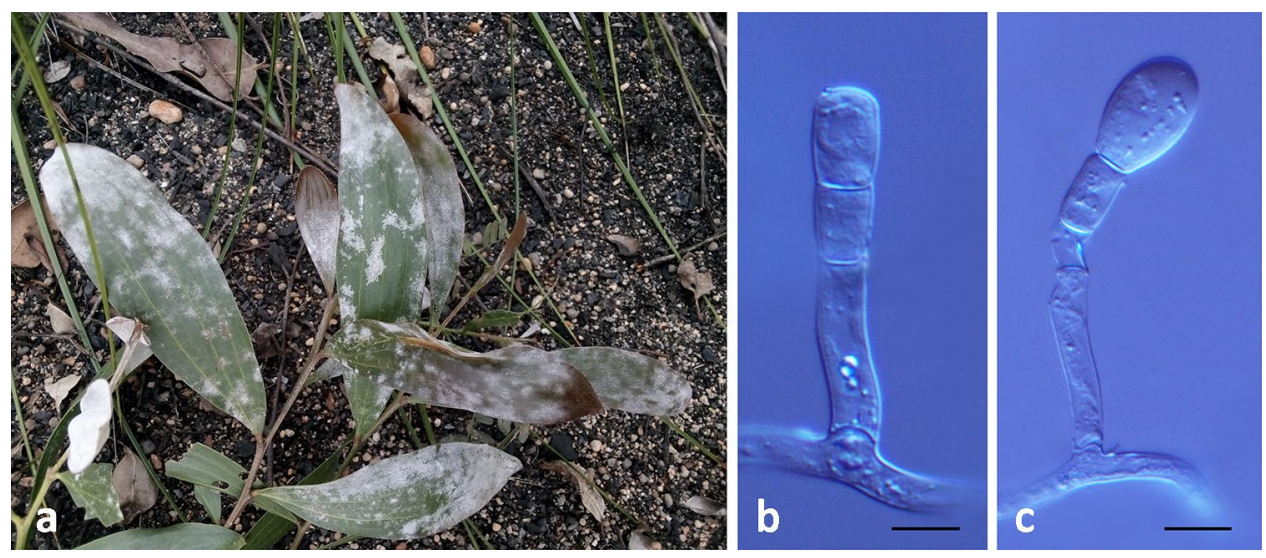

according to the manufacturer's instructions. The internal transcribed spacer (ITS) region of the nuclear ribosomal DNA (nrDNA) of the powdery mildew fungus was amplified from four DNA samples during a nested PCR as described by Kiss et al. (2020). The first PCRs used the powdery mildew-specific primers PMITS1 and PMITS2 developed by Cunnington et al. (2003). The nested reactions were done with the universal fungal primers ITS1-F (Gardes and Bruns 1993) and ITS4 (White et al. 1990). PCR products of the nested reactions were purified and sequenced by Macrogen Inc. (Seoul, Korea) with primers ITS1-F and ITS4. Sequences were compiled from chromatograms following visual inspections for potential polymorphisms to identify any potential intra-sample variations in the nrDNA ITS sequences reported in some powdery mildews (Kovacs et al. 2011). Consensus sequences were trimmed and assembled with Geneious Prime 2019.1.3 (Biomatters Ltd.), and deposited in NCBI GenBank under accession number MW293874. These were identical to over 20 ITS sequences of Erysiphe quercicola available in GenBank, and Maximum Likelihood phylogenetic analysis conducted using MEGAX (Kumar et al. 2018) further confirmed the identity of the fungus (Fig. 2).

Erysiphe quercicola was recognised by Takamatsu et al. (2007) as a distinct taxon within the species complex $E$. alphitoides s. lat. infecting diverse oak species (Quercus spp.). Soon after its description, E. quercicola was identified on several unrelated woody hosts, such as mango (Mangifera indica), rubber tree (Hevea brasiliensis), Citrus spp., and a number of other tropical and subtropical tree species (Kirschner and Liu 2014; Takamatsu et al. 2015; DesprezLoustau et al. 2017, 2018; Meeboon and Takamatsu 2020). In Australia, E. quercicola was recorded on oak, mango, and also on the native Acacia holosericea, A. mangium, and Eucalyptus camaldulensis based on ITS sequence analyses (Limkaisang et al. 2006; Takamatsu et al. 2007, 2015). This is its first report on A. sophorae worldwide.

A recent comprehensive list of powdery mildew species identified in Australia indicated that all the species of this large group of plant pathogens, the Erysiphales, were introduced to Australia since the beginning of European colonisation of the continent (Kiss et al. 2020). Most Australian native plants have never been reported as hosts of any powdery mildews. Those that are known to be infected with these pathogens were always attacked by species introduced from overseas. Kiss et al. (2020) hypothesised that all the powdery mildew infections of plants native to Australia recorded so far have been the result of quick host range expansion events of introduced species that are known to have wide host ranges overseas. This is supported by molecular clock evidence that suggests powdery mildews emerged in the late Cretaceous (Takamatsu 2013), after the separation of Australia from Gondwana. It is likely that the powdery mildew infection of $A$. sophorae, reported here for the first time globally, is a new example of a host range expansion of E. quercicola. 
Fig. 2 Maximum-Likelihood Tree of an ITS sequence alignment using MEGAX. The scale bar shows 0.005 changes per site, and bootstrap support values from 1,000 replicates are shown at the nodes. Specimen from this study indicated in bold. Hosts and regions are indicated. Genbank accession numbers are provided in parentheses

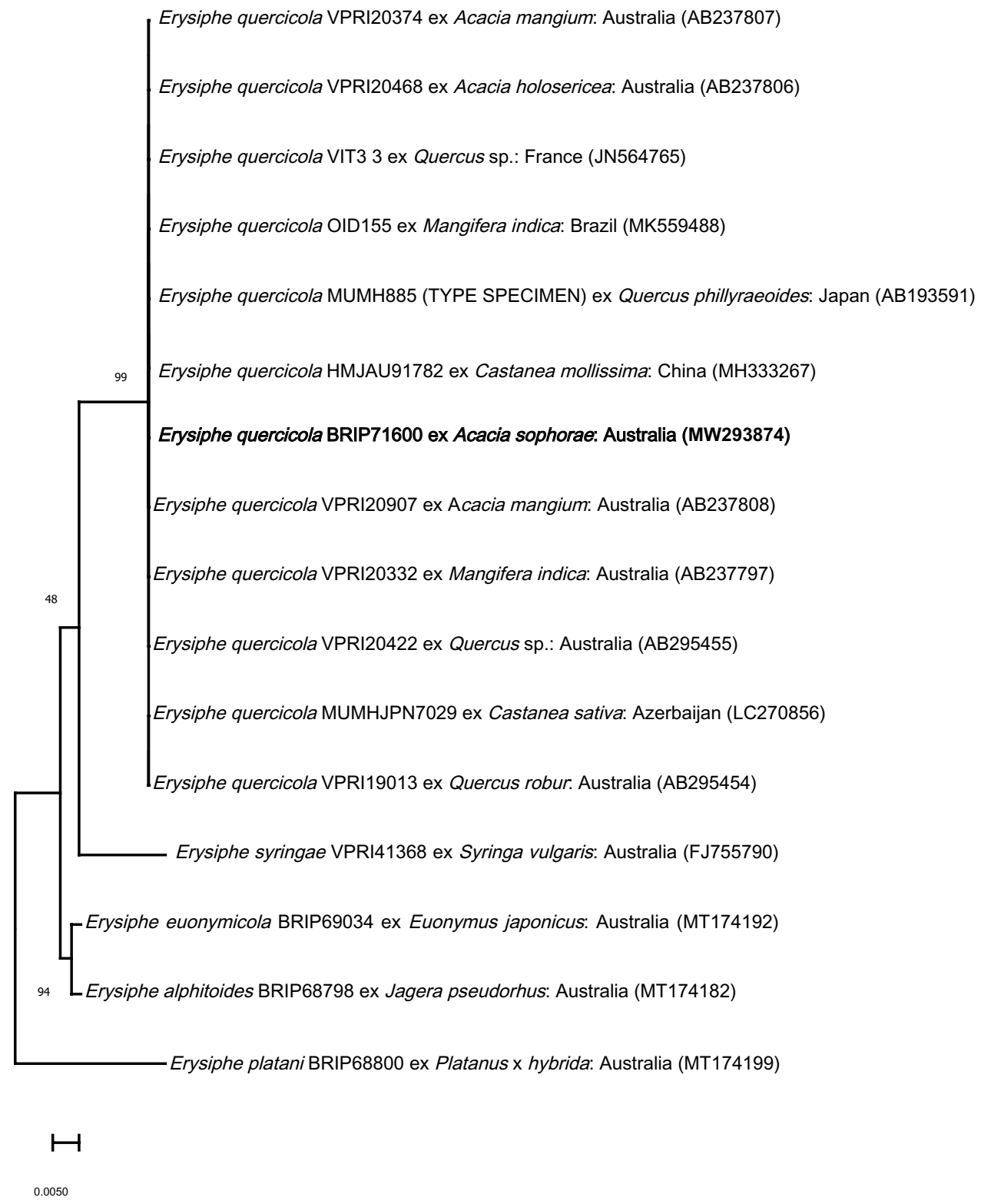

0.0050

Acknowledgements We would like to thank Mark Nemeth for assistance with image processing, Jennifer Young for taxonomical assistance and Owen Shortt who helped identify the collection site.

\section{References}

Cunnington JH, Takamatsu S, Lawrie AC, Pascoe IG (2003) Molecular identification of anamorphic powdery mildews (Erysiphales). Austral Plant Pathol 32:421-428

Desprez-Loustau M-L, Massot M, Feau N, Fort T, De Vicente A, Torés JA et al (2017) Further support of conspecificity of oak and mango powdery mildew and first report of Erysiphe quercicola and Erysiphe alphitoides on mango in mainland Europe. Plant Dis 101:1086-1093
Desprez-Loustau M-L, Massot M, Toïgo M, Fort T, Kaya AGA, Boberg $\mathrm{J}$ et al (2018) From leaf to continent: the multi-scale distribution of an invasive cryptic pathogen complex on oak. Fungal Ecol 36:39-50

Gardes M, Bruns TD (1993) ITS primers with enhanced specificity for basidiomycetes-application to the identification of mycorrhizae and rusts. Mol Ecol 2:113-118

Kirschner R, Liu WA (2014) Two new hosts of anamorphic Erysiphe quercicola: Cinnamomum camphora and Murraya paniculata. Mycoscience 55:190-195

Kiss L, Vaghefi N, Bransgrove K et al (2020) Australia: a continent without native powdery mildews? The first comprehensive catalogue indicates recent introductions and multiple host range expansion events, and leads to the re-discovery of Salmonomyces as a new lineage of the Erysiphales. Front Microbiol 11:1571

Kovács GM, Jankovics T, Kiss L (2011) Variation in the nrDNA ITS sequences of some powdery mildew species: do routine molecular 
identification procedures hide valuable information? Eur J Plant Pathol 131:135-141

Kumar S, Stecher G, Li M, Knyaz C, Tamura K (2018) MEGA X: Molecular Evolutionary Genetics Analysis across computing platforms. Mol Biol Evol 35:1547-1549

Limkaisang S, Cunnington JH, Wui LK, Salleh B, Sato Y, Divarangkoon R et al (2006) Molecular phylogenetic analyses reveal a close relationship between powdery mildew fungi on some tropical trees and Erysiphe alphitoides, an oak powdery mildew. Mycoscience 47:327-335

Meeboon J, Takamatsu S (2020) Hosts of asexual morph of Erysiphe quercicola from Thailand. Trop Plant Pathol 45:122-135

Shin HD, La YJ (1993) Morphology of edge lines of chained immature conidia on conidiophores in powdery mildew fungi and their taxonomicsignificance. Mycotaxon 46:445-451
Takamatsu S (2013) Origin and evolution of the powdery mildews (Ascomycota, Erysiphales). Mycoscience 54:75-86. https://doi. org/10.1016/j.myc.2012.08.004

Takamatsu S, Braun U, Limkaisang S, Kom-Un S, Sato Y, Cunnington JH (2007) Phylogeny and taxonomy of the oak powdery mildew Erysiphe alphitoides sensu lato. Mycol Res 111:809-826

Takamatsu S, Ito (Arakawa) H, Shiroya Y, Kiss L, Heluta V (2015) First comprehensive phylogenetic analysis of the genus Erysiphe (Erysiphales, Erysiphaceae) I. The Microsphaera lineage. Mycologia 107:475-489

White TJ, Bruns T, Lee S, Taylor J (1990) Amplification and direct sequencing of fungal ribosomal RNA genes for phylogenetics. In: Innis MA, Gelfand DH, Sninsky JJ, White TJ (eds) PCR Protocols: A Guide to Methods and Applications. Academic Press, San Diego, CA, pp 315-322 